\title{
A pilot study of the effect of low level exposure to mercury on the health of dental surgeons
}

Karen A Ritchie, Ewan B Macdonald, Richard Hammersley, Jacqueline M O’Neil, David A McGowan, Ian M Dale, Keith Wesnes

\begin{abstract}
Objectives-This project was conducted to examine whether the computerised analysis of psychomotor responses available from Cognitive Drug Research is appropriate for measuring an effect of low level exposure to mercury in dentists.

Methods-A computerised battery of psychomotor tests was given to two groups of dentists (older dentists and trainees) and to two age matched control groups. As well as the psychomotor tests, volunteers were required to complete a questionnaire to identify potential influences on psychomotor performance and to provide a sample for analysis of urinary mercury. Results-Statistical analysis of the results showed that the older dentists had slightly higher concentrations of urinary mercury although most were around background levels and they were all within occupational limits. Five of the psychomotor tests showed no differences between the performance of the four groups. The older dentists showed significantly better performance on the simple reaction time test and significantly poorer performance in the immediate word recall and delayed word recall tests.

Conclusions-Poorer performance in memory recall tests confirms previously reported studies. This together with the confirmation that this test system is a practical tool in the occupational setting suggests that a larger study of the effects of mercury exposure on dentists would be appropriate.
\end{abstract}

(Occup Environ Med 1995;52:813-817)

Keywords: dental surgeons; mercury; psychomotor performance

Previous concern in the dental profession over their exposure to mercury has been recently reawakened. ${ }^{2}$ Much of this has resulted from public concern with the amalgam fillings they have in their teeth. Those working in dental surgeries where amalgam is used on a daily basis can expect to experience considerably higher exposure levels than the general public. $^{3}$ Studies conducted in recent years have suggested that new automated methods of production of amalgam have resulted in a reduction in the urinary mercury concentrations of dental surgeons and their assistants ${ }^{4}$ compared with measurements made a decade or so before. ${ }^{5}$ There have, however, been several published studies suggesting that chronic exposure to low levels of mercury, such as would be experieñced by dentists, have an effect on psychological performance. ${ }^{68}$ Previous studies have used neuropsycholgical assessment batteries, although the validity of these instruments for detecting small psychological abnormalities has not been established. Alternatively, or in addition, some studies have used a different range of tests of cognitive and motor function. Because the tests used have not been systematic, it has not been possible to establish a defininte pattern of deficit induced by low level mercury exposure.

\section{ASSESSMENT OF SUBTLE NEUROLOGICAL DEFICITS}

The pilot study reported here used a systematic computerised cognitive and motor skills assessment system developed by Cognitive Drug Research. ${ }^{910}$ This system has been shown to be sensitive to substances and illnesses that involve small cognitive deficits, rather than gross abnormalities. It assesses a systematic range of cognitive functions known to be among the most sensitive indicators of cognitive impairment including simple reaction time, complex reaction time, vigilance, and memory. The test system also has the advantage for occupational settings of taking only about 20 minutes to do, compared with two hours or more for some "paper and pencil" neuropsychological batteries. Extensive paper and pencil assessment batteries have existed since the $1950 \mathrm{~s}$. Those in widespread use today include the Luria-Nebraska battery, ${ }^{11}$ and the Halstead-Reitan battery, ${ }^{12}$ which includes administration of both the Wechsler adult intelligence test (WAIS) and the Minnesota multiphasic personality inventory (MMPI). Although these batteries are invaluable in clinical settings, they have several disadvantages for occupational assessment. Firstly, they take a long time $(1.5-2.5$ hours for the Luria-Nebraska and longer for the Halstead-Reitan) to do. This generally makes full testing too expensive for wide screening of a workforce, and performing the batteries is usually only cost effective if there is already considerable suspicion of neurological damage. Secondly, for valid administration they require a trained and experienced tester and such may not be always available. Because of these practical difficulties, some studies have extracted parts of the test batteries for use. For 
example, the memory sub-scales of the WAIS. Interpreting scores from partial tests can be problematic and the normative data for the entire test should not be used for comparison. A final problem is that the batteries were initially developed to assess fairly gross brain damage, as might be caused by a lesion or aneurysm. The batteries' abilities to detect small deficits caused by chemicals or other more subtle agents has not been shown.

Because of these problems, with the advent of computers a large number of computerised tests of motor and cognitive performance have been developed. As with the pencil and paper batteries, the ideal computer battery should assess a comprehensive range of psychological functions and be validated. Often individual tests are used without validation and these can range from those with surface validity only (they look as if they test something important and relevant, but may not) to those that can only be described as whimsical. ${ }^{13}$

The Cognitive Drug Research computerised assessment system is comprehensive, has been extensively validated, and has been shown to detect relatively subtle deficits such as those caused by prescribed drugs, aging, or early stage dementia. ${ }^{14}{ }^{15}$ Unlike the paper and pencil batteries, it can be given in under half an hour.

The pilot study described here was designed to determine the suitability of the Cognitive Drug Research test system for use in an occupational setting, and to assess if these tests were sensitive enough to measure the effects of low levels of mercury on an exposed population.

\section{Methods}

The study population was composed of a total of 39 dentists from the west of Scotland, of which 19 were vocational trainees-that is, they had completed their degrees and were undergoing a year of supervision before registration. The other 20 dentists were vocational trainers-that is, experienced dentists. The control population were mainly qualified doctors. In the first instance general practitioners were invited to act as the control population. A poor response from this group required that, in addition, some junior hospital medical staff and a group of occupational physicians were enlisted into the control group. This control group fulfilled the criteria for having similar educational backgrounds as the study group. Both groups were required to complete a questionnaire. This asked for a few personal details (age, sex, and general health), their alcohol consumption in the previous week, and for details of any medication taken regularly. In addition the control group were asked if they had any acute exposure to mercury from, for example, a broken thermometer. The dentists were asked for details of amalgam preparation and storage in the surgery, and for details of any mercury spillages they may have experienced. Both groups were asked also to complete the 12 question version of the general health questionnaire.

\section{MERCURY ANALYSIS}

To establish the level of mercury exposure of both study and control populations the participants were asked to provide a urine sample. Urine analysis gives an indication of the person's exposure to mercury over the previous three to four weeks. These samples were analysed for mercury concentration at the Biochemistry Department of Glasgow Royal Infirmary. Mercury content of the samples was measured by cold vapour atomic absorption spectroscopy and the results related to creatinine content to take into account the person's urine concentration.

\section{PSYCHOMETRIC PERFORMANCE}

A computerised assessment system provided by Cognitive Drug Research was used to measure the neurobehavioural performance of each volunteer. The testing was conducted with portable laptop computers linked to response boxes that comprised two buttons, one marked YES and one marked NO.

The following tests were used:

\section{Word recall}

Fifteen words were presented on the screen at a rate of one every two seconds. The volunteer was then given 60 seconds to write down as many as could be recalled.

\section{Simple reaction time}

The word YES was presented at random intervals on the screen. The volunteer was then required to press the YES button on the response box as quickly as possible each time the word appeared.

\section{Number vigilance}

A digit was presented on the right hand side of the screen. A series of digits was then presented in the middle of the screen and the volunteer was required to press the YES button as quickly as possible whenever the two digits matched.

\section{Choice reaction time}

The words YES and NO were presented at random intervals on the screen. The volunteer was then required to press the corresponding response button as quickly as possible.

\section{Spatial memory}

Volunteers were presented with a picture of a house with 20 windows. Some of the rooms were lit and some were not lit. The volunteers were then presented with the same house with only one room lit and were required to press the YES button if this room had been lit in the original house, and to press the NO button if it had not.

\section{Memory scanning}

A series of five digits were presented that the volunteer was asked to memorise. This was followed by a series of random digits after each of which the volunteer was required to press the YES button if it had been one of the original five digits shown and the NO button if it had not been one of the original five digits. 
Delayed word recall

Volunteers were requested to write down as many of the 15 words with which they had been presented at the beginning of the tests.

Word recognition

The list of 15 words originally presented together with a number of distracter words were randomly presented on the screen. The volunteers were required to identify if each word had been present in the original list and press the YES and NO buttons as appropriate.

The computerised test ran for 15-20 minutes with the results being recorded on two separate floppy discs for each person tested. One of each of these discs and the word recall response sheets were returned to Cognitive Drug Research for analysis. The subjects were allowed to become familiar with the control box but were not given the opportunity of a full practice session.

Raw data obtained on the results of the eight tests already described together with the responses to the questionnaire material and the results of mercury testing were analysed at the Robertson Centre for Biostatistics at the University of Glasgow.

\section{Results}

Table 1 describes the characteristics of the volunteer groups. Age was not well matched as the newly qualified dentists were all between the ages of 22 and 24 years whereas the group of junior doctors had a wider range of ages. The effect of age was taken into account in the statistical analysis described later. This was achieved by one way analysis of covariance with age as a covariate.

\section{MERCURY ANALYSIS}

Table 2 shows the urinary mercury concentrations of all the volunteers taking part in the study. Mercury concentrations of less than 5 $\mathrm{nmol} / \mathrm{mmol}$ creatinine are considered to be background concentrations. Three of the older dentists and one of the younger dentists had concentrations above the background (although well below the currently accepted occupational limit of $120 \mathrm{nmol}$ mercury $/ \mathrm{mmol}$ creatinine). Also, one of the older controls had a higher than background exposure to mer-

Table 1 Characteristics of study and control groups

\begin{tabular}{llrcl}
\hline & $n$ & Men & Women & $\begin{array}{l}\text { Age } \\
\text { median (range) }\end{array}$ \\
\hline Older dentists & 20 & 20 & 0 & $40(33-52)$ \\
Younger dentists & 19 & 7 & 12 & $23(22-24)$ \\
Older controls & 20 & 15 & 5 & $44(31-56)$ \\
Younger controls & 20 & 8 & 12 & $28(23-37)$ \\
\hline
\end{tabular}

Table 2 Urinary mercury concentrations

\begin{tabular}{ll}
\hline & $\begin{array}{l}\text { Mercury/creatinine ratio (nmol/mmol) } \\
\text { median (range) }\end{array}$ \\
\hline Older dentists & $3.65(2 \cdot 5-17 \cdot 6)$ \\
Younger dentists & $1 \cdot 8(0 \cdot 7-16 \cdot 6)$ \\
Older controls & $0.95(0 \cdot 2-15 \cdot 0)$ \\
Younger controls & $1 \cdot 25(0 \cdot 5-6 \cdot 1)$ \\
\hline
\end{tabular}

Table 3 General health questionnaire results

\begin{tabular}{ll}
\hline & Total score (mean (SD)) \\
\hline Older dentists & $1.65(2 \cdot 03)$ \\
Younger dentists & $1.28(1.93)$ \\
Older controls & $1.10(1 \cdot 74)$ \\
Younger controls & $1.45(2 \cdot 01)$ \\
\hline
\end{tabular}

cury. Table 2 shows that the median measures of exposure was highest for the older dentists and lowest for the older control group.

Measurement of mercury exposure by biochemical analysis of urinary concentrations did not show levels of variation that allowed dose response curves of mercury exposure against test scores to be constructed. The older dentists were assumed to have experienced long term low level mercury exposure as a result of their continuous working with amalgam in their dental surgeries.

\section{GENERAL HEALTH QUESTIONNAIRE}

Analysis of the scores of the general health questionnaire showed no significant differences in the scores of the four groups of volunteers (table 3).

The answers to questions relating to general health included in the questionnaire did not show any significant differences between the groups. A slightly larger proportion of older dentists reported gastrointestinal disturbances than did older controls and a larger proportion of younger dentists reported sleep disturbance than did the younger controls. Answers to questions relating to loss of appetite, concentration levels, memory disturbance, and tiredness showed little or no variation between the groups.

\section{PSYCHOMETRIC PERFORMANCE}

Differences in performance between the groups were found in three of the eight tests. Table 4 shows the means (SDs) for these tests. As the ages of the controls when compared with the dentists showed some variation, $t$ tests conducted on the data were age adjusted by one way analysis of covariance.

\section{Simple reaction time}

Younger dentists and controls did not differ on this test, but older dentists had significantly faster simple reaction times than older controls $(P<0.02)$. This indicates that the older dentists performed better on this task which primarily measures motor skills.

\section{Memory tasks}

Those memory tasks with a component of immediate memory-that is, number vigilance and memory scanning - did not differ between the groups, nor did recognition tasks (word recognition and spatial memory). Older dentists performed worse than older controls on both immediate word recall $(P<0.05)$ and delayed word recall $(P<0.05)$. As expected, delayed recall was somewhat poorer than immediate recall for all groups and this tendency was to some extent more notable for older subjects. 
Table 4 Psychomotor test results

\begin{tabular}{|c|c|c|c|c|}
\hline & $\begin{array}{l}\text { Older dentists } \\
\text { mean }(S D)\end{array}$ & $\begin{array}{l}\text { Older controls } \\
\text { mean }(S D)\end{array}$ & $\begin{array}{l}\text { Younger dentitsts } \\
\text { mean }(S D)\end{array}$ & $\begin{array}{l}\text { Younger controls } \\
\text { mean }(S D)\end{array}$ \\
\hline \multirow{3}{*}{$\begin{array}{l}\text { Simple reaction } \\
\text { time (ms) } \\
\text { Immediate word recall } \\
\quad(\% \text { correct) } \\
\text { Delayed word recall } \\
\text { (\% correct) }\end{array}$} & $241(22 \cdot 34)$ & $271(36 \cdot 02)$ & $231(21 \cdot 84)$ & $249(22 \cdot 20)$ \\
\hline & $39(11 \cdot 24)$ & $42(9 \cdot 88)$ & $47(12 \cdot 27)$ & $51(8.09)$ \\
\hline & $31(10 \cdot 60)$ & $35(10 \cdot 17)$ & $43(12 \cdot 52)$ & $46(11 \cdot 80)$ \\
\hline
\end{tabular}

The scores for the three measures of psychometric performance listed in table 4 were then plotted against information gained from the questionnaire about alcohol consumption, amalgam preparation, and mercury exposure as a result of experiencing a spillage. There was no correlation between any of these measures and the pattern of test scores already described.

\section{Discussion}

The test results showed two effects. Older dentists reacted faster (better) than controls. It is implausible that this was due to mercury exposure. Instead, it may have been due to their highly practised manual dexterity skills. Recall from memory was less accurate among older dentists, but recognition was unaffected. Recognition tasks are generally easier than recall tasks so recall tasks tended to be impaired first. Furthermore, effects on recall, but not recognition generally suggest a specific impairment of retrieval from memory, as opposed to encoding or storage deficits. The effect was modest and might have been due to mercury exposure, or to other differences between older dentists and controls.

These alterations in psychometric performance were small and mostly within the range of normal variation. The changes in memory function agree with other published data. If these changes were indeed the result of exposure to mercury, working practices among the dental profession would have to be assessed and reconsidered in the light of the evidence.

The results of this pilot project partly support the results of previous publications in that there were significant disturbances in the cognitive abilities of a group of workers who have experienced long term exposure to low concentrations of mercury. ${ }^{79}$ There was not enough variation in the levels of mercury exposure as measured by biochemical analysis of urine samples to hypothesise that there might be a dose response relation between this and the psychometric test scores. Indeed no relation was found when mercury concentrations were plotted against the relevant scores. The group of older dentists will have experienced chronic exposure to low levels of mercury during their working lives and this group were distinct in that they showed significant variations in recall from memory. The variations in performance were compared with possible confounders-namely, alcohol consumption, amalgam preparation, and unusual exposure due to mercury spillage. No correla- tions between any of these confounders and the psychometric scores could be found.

The only measurement of mercury exposure was the analysis of urinary mercury concentrations. Those dentists with the highest mercury concentrations were offered a repeat test and subsequent environmental monitoring of their surgeries if necessary. The variations in mercury concentrations were low, which may be explained by the fact that the group of older dentists studied here are involved in training newly qualified dentists and are selected as such on the basis of their good working practices. A randomly selected sample of all dentists working in the west of Scotland would probably show greater variation in their mercury exposure levels.

The small sample and low levels of mercury exposure found limit the conclusions that can be drawn. The purpose of the project described here was twofold; firstly, to determine the feasibility of using the computerised cognitive testing system described here in an occupational setting; secondly, to establish if these tests were likely to be sensitive enough to measure the variations in psychomotor performance previously reported in groups exposed to mercury.

The Cognitive Drug Research testing system has been shown to be an appropriate tool for conducting cognitive testing within an occupational setting in that it is portable and the tests were found to be very acceptable by most of the volunteers. The correlation between the alterations in memory function found in the group exposed to mercury studied here and those previously reported suggests that the testing system is indeed sensitive enough. The levels of mercury exposure were well within occupational limits and the overall changes in psychomotor performance were small and inconclusive. Therefore a study of a much larger group of dentists would be required to assess any effect on the central nervous system resulting from chronic low level exposure to mercury.

This study was carried out with support from the Home and Health Department of the Scottish Office. We thank Dr J Warren, Department of Biochemistry, Glasgow Royal Infirmary, and Dr G Murray, Robertson Centre for Biostatistics, University of Glasgow.

Pleva J. Dental mercury-A public health hazard. Rev Environ Health 1994;10:1-27.

2 Gordon P, Eley B. Amalgam questions and answers. $\mathrm{Br}$ Dental f 1993;175:153-4.

3 Enwonwu CO. Potential health hazard of use of mercury in dentistry. Critical Review of the Literature on Environmental Research 1987;42:257-274.

4 Skare I, Eng L, Bergström T, Engqvist A, Weiner JA. Mercury exposure of different origins among dentists and dental nurses. Scand $\mathcal{F}$ Work Environ Health 1990;16: 340-7.

5 Naleway C, Sakaguchi R, Mitchell E, Muller T, Ayer WA, Hefferren JJ. Urinary mercury levels in US dentists 1975-1983: review of health assessment program. $\mathcal{F} \mathrm{Am}$ Dental Assoc 1985;111;37-42.

6 Ngim CH, Foo SC, Boey KW, Jeyaratnam J. Chronic neurobehavioural effects of elemental mercury in dentists. $B$ f Ind Med 1992;49:782-90.

7 Piikivi L, Hänninen H, Martelin T, Mantere P. Psychological performance and long-term exposure to mercury vapors. Scand $\mathcal{F}$ Work Environ Health 1984;10:35-41.

8 Roels H, Lauwerys R, Buchet JP, Bernard A, Barthels A, Oversteyns M, Gaussin J. Comparison of renal function and psychomotor performance in workers exposed to elemental mercury. Int Arch Occup Environ Health 1982; 50:77-93.

9 Wesnes K, Simmons D, Rook M, Simpson P. A double- 
blind placebo-controlled trial of tanakin in the treatment of idiopathic cognitive impairment in the elderly. Human Psychopharmacology 1987;2:159-69.

10 Simpson PM, Wesnes KA, Christmas L. A computerized system for the assessment of drug-induced performance system for the assessment of drug-induced performance
changes in young, elderly, or demented populations. $B r F$
Clin Pharmacol $1989 ; 27: 711-2$.

11 Golden CJ, Hammecke T, Purisch A. Diagnostic validity of a standardized neurophsycological battery derived from Luria's neuropsychological test. F Consult Clin Psychol 1978;46:1358-65.

12 Boll TJ. Diagnosing brain impairment. In: BB Wolman, ed.
Clinical diagnosis of mental disorders: a handbook. New York: Plenum, 1978.

13 Hindmarch I. Editorial: psychometrics and psychopharmacology. Human Psychopharmacology 1989;4:79-80.

14 Simpson PM, Wesnes K, Christmas L. Computerized cognitive assessment systems to study the effects of nootropics in aged and demented populations. Psychopharmacology (Berl) 1988;96:243S.

15 Wesnes K, Simpson PM, Christmas L. A microcomputerized system for evaluating the cognitive actions of drugs in the young, elderly and demented. Eur $\mathcal{F}$ Clin Pharmacol 1989;36:A38.

\section{Vancouver style}

All manuscripts submitted to Occup Environ Med should conform to the uniform requirements for manuscripts submitted to biomedical journals (known as the Vancouver style.)

Occup Environ Med, together with many other international biomedical journals, has agreed to accept articles prepared in accordance with the Vancouver style. The style (described in full in the BMF, 24 February 1979, p 532) is intended to standardise requirements for authors.

References should be numbered consecutively in the order in which they are first mentioned in the text by Arabic numerals above the line on each occasion the reference is cited (Manson ${ }^{1}$ confirmed other reports $^{2-5} \ldots$. .). In future references to papers submitted to Occup Environ Med should include: the names of all authors if there are seven or less or, if there are more, the first six followed by $e t$ al; the title of journal articles or book chapters; the titles of journals abbreviated according to the style of Index Medicus; and the first and final page numbers of the article or chapter. Titles not in Index Medicus should be given in full.

Examples of common forms of references are:

1 International Steering Committee of Medical Editors, Uniform requirements for manuscripts submitted to biomedical journals. Br Med F 1979;1:532-5.

2 Soter NA, Wasserman SI, Austen KF. Cold urticaria: release into the circulation of histamine and eosinophil chemotactic factor of anaphylaxis during cold phil chemotactic factor of anaphylaxis duri 1 .

3 Weinstein L Swartz MN. Pathogenic properties of invading micro-organisms. In: Sodeman WA Jr, Sodeman WA, eds. Pathologic physiology, mechanism of disease. Philadelphia: W B Saunders, 1974:457-72. 